\title{
Use of the Internet as a prevention tool against cognitive decline in normal aging
}

Clinical Interventions in Aging

9 September 2016

Number of times this article has been viewed

\author{
Blanka Klimova \\ Department of Applied Linguistics, \\ Faculty of Informatics and \\ Management, University of Hradec \\ Kralove, Hradec Kralove, Czech \\ Republic
}

\begin{abstract}
Recent demographic trends indicate that older people appear to be one of the fastest growing population groups worldwide. In the year 2000, people older than 65 years represented $12.4 \%$ of the population. This number is expected to rise to $19 \%$ by 2030 , particularly in developed countries. Therefore, there is sustained effort at both national and international levels to prolong the active life of these people as long as possible. Since the present older generation at the age of 55 years is already digitally literate, the use of technologies is one of the solutions. The purpose of this study is to discuss the role of the Internet in the prevention of cognitive decline in normal aging. The author examines clinical studies that exploit the use of the Internet, including online training programs, in the prevention of cognitive decline in healthy older individuals. The findings of the clinical studies indicate that the use of the Internet, especially online cognitive training programs, may have a positive effect on the improvement of cognitive functions in healthy older adults. Nevertheless, larger sample longitudinal randomized controlled clinical trials aimed at the prevention of cognitive decline among healthy older adults are needed.
\end{abstract}

Keywords: healthy older individuals, Internet, prevention, cognitive functions, training

\section{Introduction}

The elderly appear to be one of the fastest growing population groups worldwide. Never before in human history has our planet included such a large percentage of old people. As late as 1930, America's older population numbered fewer than 7 million - only $5.4 \%$ of the population. In the year 2000 , people older than 65 years represented $12.4 \%$ of the population and this number is expected to rise to $19 \%$ by 2030 , particularly in developed countries. ${ }^{1}$

Cognitive skills play an important role in older people's daily functioning, such as remembering appointments and driving. Unfortunately, some of these cognitive skills decline during the process of aging. In spite of the fact that cognitive aging varies among different individuals, there are some common features. ${ }^{2}$ Research studies show that changes in the cognitive domain are based on crystallized and fluid intelligence. ${ }^{3-5}$ Crystallized intelligence is the ability to exploit acquired skills and knowledge such as formulation of general information, use of vocabulary, reading comprehension, analogs, and numerical reasoning. This ability is more or less stable and does not change with age. In fact, it can be even enhanced with advancing age at a rate of 0.02-0.003 SDs per year at the age of 60 years and 70 years. ${ }^{6}$ In contrast, fluid intelligence, which usually starts in middle age, significantly influences the cognitive functions because this intelligence requires speed processing, problem-solving skills, working memory, abstract reasoning, and learning. ${ }^{7}$ This ability usually declines at a rate of -0.02 per year
Correspondence: Blanka Klimova Department of Applied Linguistics, Faculty of Informatics and Management, University of Hradec Kralove, Rokitanskeho 62, 50003, Hradec Kralove, Czech Republic

Tel +420737928745

Email blanka.klimova@uhk.cz 
and considerably affects older people's performance of daily activities and independent living. ${ }^{6,8}$

In addition, there are a number of other aspects that can negatively influence cognitive functions in aging. These include sensory factors (eg, impaired vision or hearing), health-related factors (eg, pain or arthritis), changes in mood (eg, depression or anxiety), and drugs that can have side effects (eg, drowsiness). ${ }^{5}$ Thus, there is currently a general trend to delay these negative changes of cognitive decline by effective nonpharmacological approaches. ${ }^{9}$ Additionally, information and communication technologies (ICT) can be one of the noninvasive solutions to the prevention of cognitive decline in the process of normal aging. The use of technologies is also supported by three major current trends:

- an increase in the number of older people worldwide;

- ICT as a tool for providing older people with the promise of greater independence;

- the generation of "baby boomers" approaching retirement being relatively comfortable using ICT; they will bring many technology-related skills into their retirement years. ${ }^{10}$

In fact, the older generation is now much more digitally literate in the use of ICT than they were 2 decades ago. ${ }^{11,12}$ Heart and Kalderon ${ }^{13}$ stated that $80 \%$ of older people have fairly easy access to computers. Recent research studies also reveal that there is a significant increase in the use of ICT, especially the Internet, for health purposes. ${ }^{14-18}$ This concept of using the Internet to enable health care and improve health in the population is called e-Health. ${ }^{19}$ At present, e-Health shows big potential for older people because it can enable easier access to better and more effective health care. de Veer et $\mathrm{al}^{20}$ reported that older people start to be open-minded toward the use of e-Health applications. Furthermore, Bujnowska-Fedak ${ }^{15}$ stated that although the main users of the Internet are young people, the key users of online health services are older adults. This is also confirmed by the Italian study ${ }^{17}$ and the German study ${ }^{18}$ in which more than a half of the seniors admitted using the Internet in search for healthrelated information. The Kaiser Family Foundation ${ }^{21}$ survey presented that older people use selected e-Health services that include, for example, obtaining information on their health, receiving reminders for scheduled visits, medication instructions, and consulting a doctor at a distance. Furthermore, they use Internet for researching health information about proper nutrition, exercise or weight issues, diseases, such as cancer, heart disease, and arthritis, high cholesterol, and health providers. Bujnowska-Fedak ${ }^{15}$ also added accessing and managing personal health records, participating in forums on self-help groups focusing on health and illness, and ordering medicine and other medicinal products.

In addition, the Internet use may promote health literacy skills through providing opportunities for health knowledge acquisition, improving other cognitive functions such as reasoning skills, providing social benefits through social media and networking sites, and training the specific navigational and digital skills required to use the Internet. ${ }^{22}$

Thus, the purpose of this study is to discuss the role of the Internet in the prevention of cognitive decline in normal aging. The author examines clinical studies that exploit the use of the Internet, including online training programs, in the prevention of cognitive decline in healthy older individuals.

\section{Methods}

The methodology of this review study is based on the study of Moher et $\mathrm{a}^{23}$ and the study of Kurz and Baelen. ${ }^{24}$ The main method was a systematic review whose aim was to find the research studies on the basis of the keywords in five databases: Web of Science, ScienceDirect, Springer, Scopus, and MEDLINE. This review was conducted in the period from 2010 to 2015 for the following keywords: "use of the Internet" AND "cognitive decline in normal aging". Altogether, 2,037 studies were found via the database search and 154 studies via other sources, which included conference proceedings and books outside the scope of the databases described earlier. After a thorough review of the titles, duplication, and abstracts of the selected studies, only 42 studies remained for the full-text analysis. After that, eight clinical studies were identified. The study was included if it matched the corresponding period, ie, from 2010 to 2015. The selection period starts with the year of 2010 since this is the year when the clinical trials conducted among older adults started to appear due to older individuals being more digitally literate and able to use the Internet on a daily basis. ${ }^{11}$ Thus, the study was included if it matched the corresponding period, ie, from 2010 to 2015; if it involved healthy older people and focused on the use of the Internet, especially online training programs. The remaining selected theoretical articles, review articles, and book chapters were exploited in the discussion and in the introduction for the exploration of the research topic and comparison of findings.

Figure 1 illustrates the selection procedure of the final number of studies, which was done in the following four steps:

- identification (identification of the relevant studies on the basis of the keywords and, consequently, on the basis of the titles);

- duplication check (the same articles were included only once); 


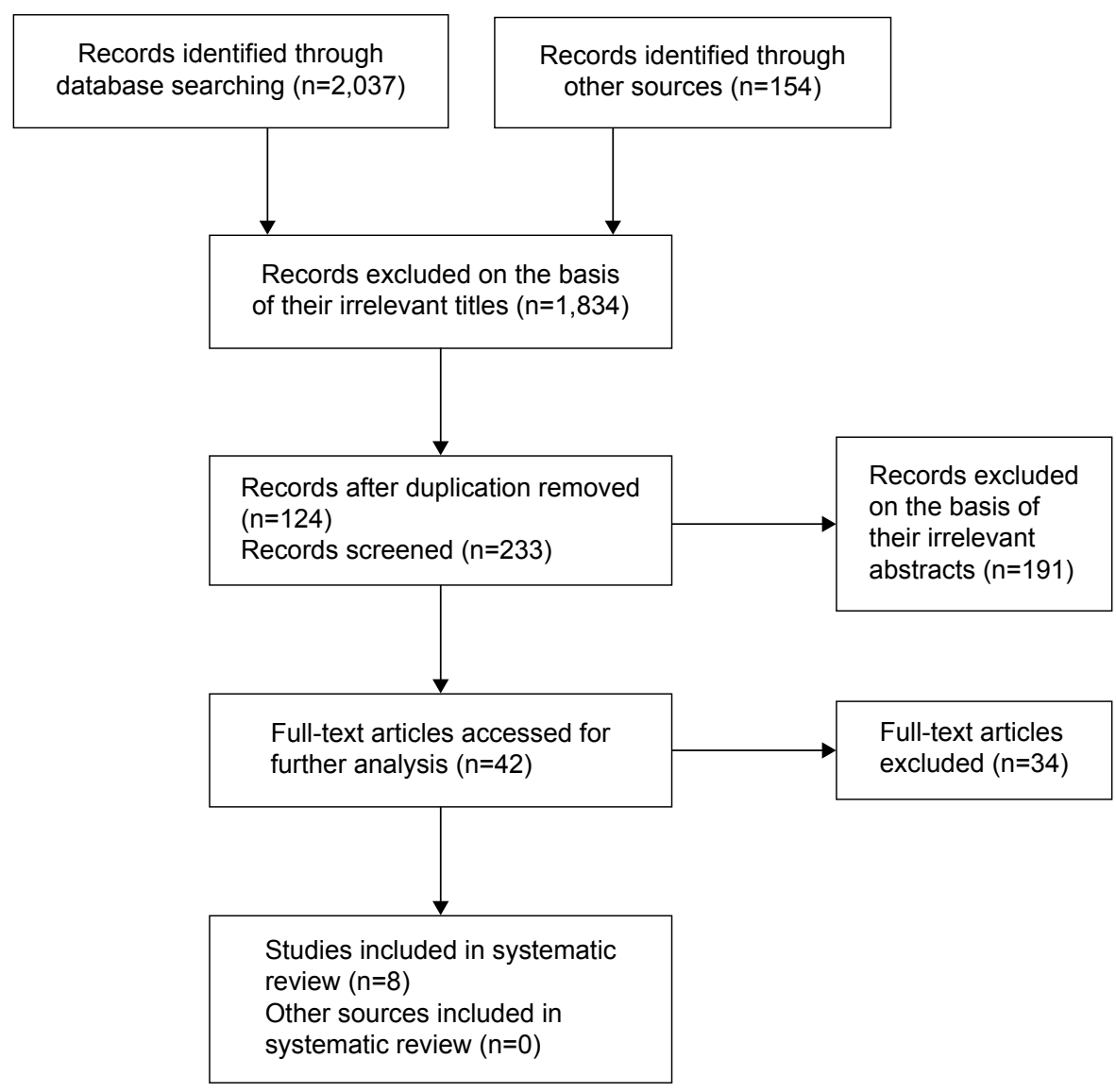

Figure I Results of the systematic review.

- assessment of relevancy (verification on the basis of abstracts whether the selected study corresponds to the set goal);

- after the exclusion of the irrelevant studies, 42 sources were analyzed and 34 eventually excluded.

\section{Findings}

Altogether, eight clinical studies focusing on the research topic were detected. The studies were included if the Internet/ online intervention activities were involved and if participants were healthy older individuals (usually $>60$ years) although in two cases the intervention group also comprised subjects with mild cognitive impairment. The research studies had to cover the designated period from 2010 to 2015. In addition, they had to be written in English. Four of the clinical studies were randomized controlled trials, which means that the efficacy of the treatment of the intervention group could have been compared with the control group; two were longitudinal cohort studies, one was a randomized clinical study, and one was a pilot study. The efficacy of the intervention treatment in the studies was predominantly measured with available validated cognitive assessment tools such as a computerized cognitive assessment battery. One of the most reliable tools is, for example, Brain Aging Monitor-Cognitive Assessment Battery. ${ }^{25}$ As far as the intervention tool is concerned, five of the clinical studies focused on online cognitive training programs, one on the Internet-based conversation, one on the use of the Internet/email, and one on the use of computers. Table 1 provides an overview and the main findings of these eight studies.

\section{Discussion}

The findings of the clinical studies described earlier show that the use of the Internet, mediating access to email, online activities such as email and cognitive training programs, with one exception, has a positive effect on the improvement of cognitive functions in healthy older adults. The findings of the study by Xavier et $\mathrm{a}^{26}$ indicated that the Internet enhances brain and cognitive reserve or leads to the engagement of more efficient cognitive networks, which may delay cognitive decline. This statement has been confirmed by other studies explored in Table 1, ie, the study of Almeida et $\mathrm{al}^{27}$ and that of Dodge et al. ${ }^{28}$ Almeida et al, ${ }^{27}$ for example, argued that the use of computers, including 


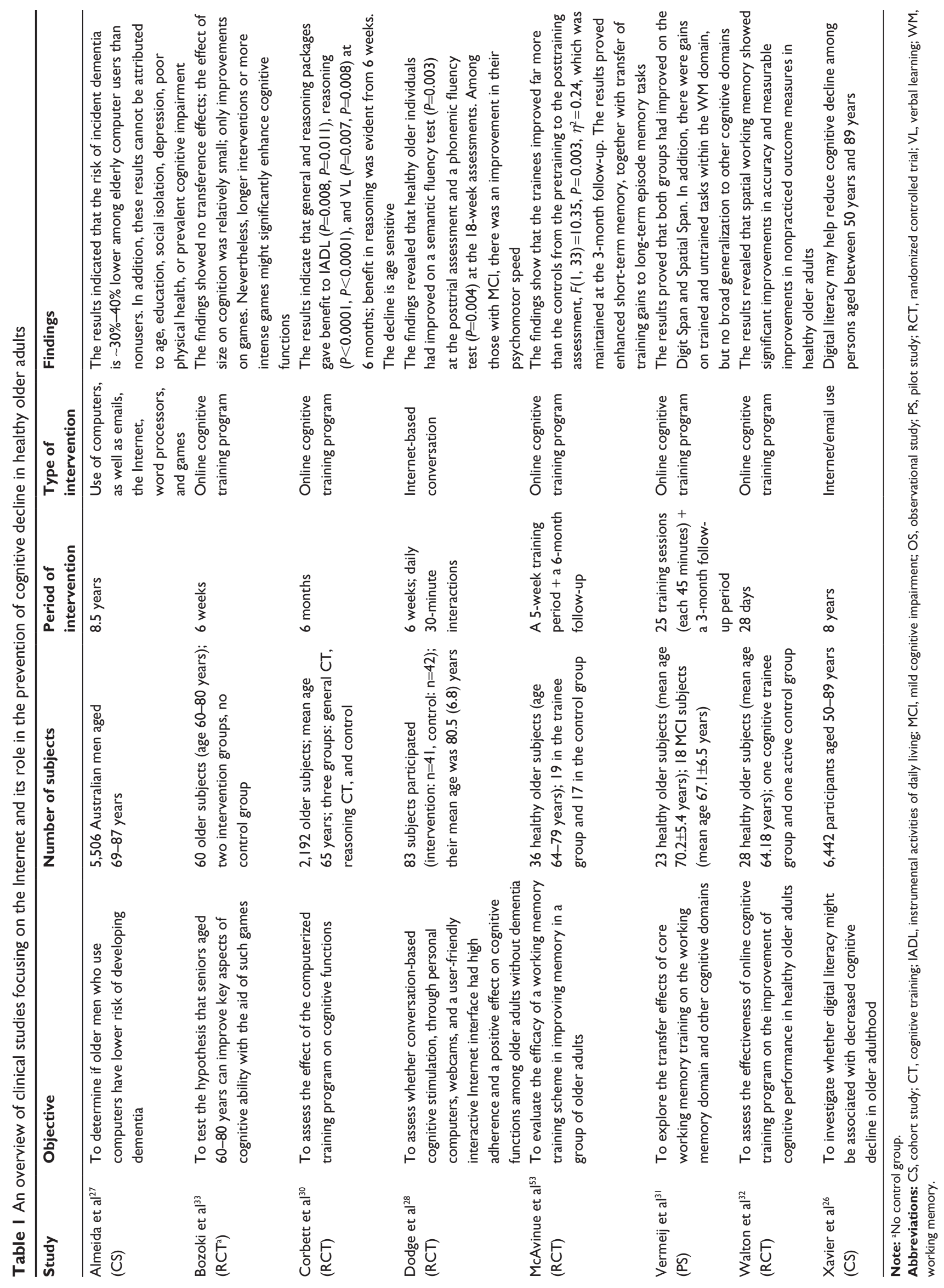


emails, the Internet, word processors, and games, may serve as an appropriate intervention tool against the development of dementia. As this study proved, the risk of incident of dementia was $\sim 30 \%-40 \%$ lower among elderly computer users than nonusers. This is in compliance with another research study by Tun and Lachman, ${ }^{29}$ who reported that the use of computers has been connected with enhanced cognitive functioning in adulthood and old age. In addition, the reviewed study by Xavier et $\mathrm{al}^{26}$ claimed that the use of the Internet, ie, digital literacy, may have a positive impact on healthy behaviors such as physical activities, higher consumption of fruits and vegetable, and less smoking among older individuals.

Moreover, the intervention of online cognitive training programs presented in Table 1, which can be done, thanks to the Internet access and digital literacy of older adults, may also contribute to the improvement of certain cognitive functions. The findings demonstrate the enhancement especially in the area of reasoning skills and short-term memory with transfer effects on nonpracticed tasks. ${ }^{30-32}$ However, the findings of the most of the reviewed clinical studies in Table 1 illustrate that the samples of the subjects using the Internet, especially doing online based activities, are relatively small and the intervention period is short. Therefore, larger sample longitudinal randomized controlled clinical trials aimed at the use of the Internet in the prevention of cognitive decline among healthy older adults are needed. This conclusion is also supported by other reviewed studies such as those of Bozoki et al, ${ }^{33}$ Haesner et al, ${ }^{34}$ and Lampit et al, ${ }^{35}$ who believe that longer and more intense interventions might significantly enhance cognitive functions.

Moreover, research studies conducted in the area of the prevention of cognitive decline include other noninvasive intervention approaches such as physical activities, adherence to the Mediterranean diet, Chinese herbal medicine, playing a musical instrument, and learning a new foreign language. ${ }^{36-44}$ Most preferably, these activities, including the use of the computer, ie, the Internet, should be done simultaneously. Anderson-Hanley et $\mathrm{a}^{45}$ stated that there is a much bigger potential for the delay of cognitive decline if, for example, cognitive and physical exercises are performed at the same time. They can also have positive effects on psychic problems such as mood improvement, removal of agitation or anxiety, and strengthening of overall fitness. ${ }^{46,47}$

\section{Conclusion}

The findings of the reviewed research studies suggest that the use of the Internet, especially online cognitive training programs, might have a positive effect on the improvement of cognitive functions in healthy older adults. In addition, the use of the Internet, including online cognitive training programs, seems to be beneficial in several ways: it is a noninvasive, in many cases, personalized intervention, and cost-effective in the sense of widespread dissemination and reduction of administration and treatment costs. ${ }^{48-50}$ Nevertheless, more randomized controlled clinical trials should be conducted to establish conclusive efficacy of these intervention approaches such as the use of the Internet and online cognitive training programs in the prevention and delay of cognitive decline among healthy older individuals.

The limitations of this review study consist in the lack of available clinical studies on the research issue and different methodologies of the included publications. This might result in the overestimated effects of the use of the Internet in the prevention of cognitive decline, which can consequently have a negative impact on the validity of these reviewed studies. ${ }^{51,52}$

\section{Acknowledgment}

The study was supported by the project Excellence (2016/17) at the Faculty of Informatics and Management of the University of Hradec Kralove, Czech Republic.

\section{Disclosure}

The authors report no conflicts of interest in this work.

\section{References}

1. Transgenerational Design Matters [webpage on the Internet]. The Demographics of Aging; 2009. Available from: http://transgenerational. org/aging/demographics.htm. Accessed May 24, 2016.

2. Wisdom NM, Mignogna J, Collins RL. Variability in Wechsler Adult Intelligence Scale-IV subtest performance across age. Arch Clin Neuropsychol. 2012;27(4):389-397.

3. Deary IJ, Corley J, Gow AJ, et al. Age-associated cognitive decline. Br Med Bull. 2009;92:132-152.

4. Harada CN, Natelson Love MC, Triebel K. Normal cognitive aging. Clin Geriatr Med. 2013;29(4):737-752.

5. Reichman WE, Fiocco AJ, Rose NS. Exercising the brain to avoid cognitive decline. Examining the evidence. Aging Health. 2010;6(5): 565-584.

6. Salthouse T. Consequences of age-related cognitive declines. Annu Rev Psychol. 2012;63:201-226.

7. Wilson RS, Beckett LA, Barnes LL, et al. Individual differences in rates of change in cognitive abilities of older persons. Psychol Aging. 2002; 17(2):179-193.

8. Hedden T, Gabrieli JDE. Insights into the ageing mind: a view from cognitive neuroscience. Nat Rev Neurosci. 2004;5(2):87-96.

9. Klimova B, Maresova P, Kuca K. Non-pharmacological approaches to the prevention and treatment of Alzheimer's disease with respect to the rising treatment costs. Current Alzheimer Research. Epub 2016 Apr 28.

10. Virginia Assistive Technology System [webpage on the Internet] Assistive Technology and Aging. A Handbook for Virginians Who Are Aging and Their Caregivers. Available from http://www.vda.virginia gov/pdfdocs/Assistive\%20Technology\%20\&\%20Aging\%20-\%20All. pdf. Accessed May 16, 2016. 
11. Klimova B, Simonova I, Poulova P, Truhlarova Z, Kuca K. Older people and their attitude to the use of information and communication technologies - a review study with special focus on the Czech Republic (older people and their attitude to ICT). Educ Gerontol. 2016;42(5): 361-369.

12. Wu YH, Damnee S, Kerherve H, Ware C, Rigaud AS. Bridging the digital divide in older adults: a study from an initiative to inform older adults about new technologies. Clin Interv Aging. 2015;10:193-201.

13. Heart T, Kalderon E. Older adults: are they ready to adopt health-related ICT? Int J Med Inform. 2013;82(11):e209-e231.

14. Smith A [webpage on the Internet]. Older Adults and Technology Use; 2014. Available from: http://www.pewinternet.org/2014/04/03/olderadults-and-technology-use/. Accessed July 11, 2016.

15. Bujnowska-Fedak MM. Trends in the use of the Internet for health purposes in Poland. BMC Public Health. 2015;15:194.

16. Wangberg S, Andreassen H, Kummervold P, Wynn R, Sørensen T. Use of the Internet for health purposes: trends in Norway 2000-2010. Scand J Caring Sci. 2009;23(4):691-696.

17. Siliquini R, Ceruti M, Lovato E, et al. Surfing the internet for health information: an Italian survey use and population choices. BMC Med Inform Decis Mak. 2011;11:21.

18. Rockmann R, Gewald H. Elderly people in eHealth: who are they? Procedia Comput Sci. 2015;63:505-510.

19. Bujnowska-Fedak MM, Pirogowicz I. Support for e-health services among elderly primary care patients. Telemed J E Health. 2014;20(8): 696-704.

20. de Veer AJ, Peeters JM, Brabers AE, Schellevis FG, Rademakers JJ, Francke AL. Determinants of the intention to use e-Health by community dwelling older people. BMC Health Serv Res. 2015;15(103):1-9.

21. Kaiser Family Foundation [webpage on the Internet]. E-Health and the Elderly: How Seniors Use the Internet for Health Information. Key findings from a National Survey of Older Americans; 2013. Available from: http://kff.org/medicare/poll-finding/e-health-and-the-elderlyhow-seniors/. Accessed July 11, 2016.

22. Kobayashi LC, Wardle J, von Wagner C. Internet use, social engagement and health literacy decline during ageing in a longitudinal cohort of older English adults. J Epidemiol Community Health. 2015;69(3): 278-283.

23. Moher D, Liberati A, Tetzlaff J, Altman DG. The PRISMA Group. Preferred reporting items for systematic review and meta-analysis: the PRISMA statement. PLoS Med. 2009;6(6):e1000097.

24. Kurz A, van Baelen B. Ginkgo biloba compared with cholinesterase Inhibitors in the treatment of dementia: a review based on metaanalyses by the Cochrane collaboration. Dement Geriatr Cogn Disord. 2004;18(2):217-226.

25. Aalbers T, Baars MA, Olde Rikkert MG, Kessels RP. Puzzling with online games (BAM-COG): reliability, validity, and feasibility of an online self-monitor for cognitive performance in aging adults. $J$ Med Internet Res. 2013;15(12): 270.

26. Xavier AJ, d'Orsi E, de Oliveira CM, et al. English longitudinal study of aging: can Internet/e-mail use reduce cognitive decline? J Gerontol A Biol Sci Med Sci. 2014;69(9):1117-1121.

27. Almeida OP, Yeap BB, Alfonso H, Hankey GJ, Flicker L, Norman PE. Older men who use computers have lower risk of dementia. PLoS One. 2012; 7(8):e44239.

28. Dodge HH, Zhu J, Mattek NC, et al. Web-enabled conversational interactions as a method to improve cognitive functions: results of a 6-week randomized controlled trial. Alzheimers Dement. 2015;1(1):1-12.

29. Tun PA, Lachman ME. The association between computer use and cognition across adulthood: use it so you won't lose it? Psychol Aging. 2010;25(3):560-568.

30. Corbett A, Owen A, Hampshire A, et al. The effect of an online cognitive training package in healthy older adults: an online randomized controlled trial. J Am Med Dir Assoc. 2015;16(11):990-997.

31. Vermeij A, Claassen JA, Dautzenberg PL, Kessels RP. Transfer effects of online working-memory training in healthy older adults and mild cognitive impairment. Alzheimers Dement. 2014;10(4):311.
32. Walton C, Kavanagh A, Downey LA, Lomas J, Camfield DA, Stough C. Online cognitive training in healthy older adults: a preliminary study on the effects of single versus multi-domain training. Translat Neurosci. 2015;6:13-19.

33. Bozoki A, Radovanovic M, Winn B, Heeter C, Anthony JC. Effects of a computer-based cognitive exercise program on age-related cognitive decline. Arch Gerontol Geriatr. 2013;57(1):1-7.

34. Haesner M, Steinert A, O'Sullivan JL, Weichenberger M. Evaluating an online cognitive training platform for older adults: user experience and implementation requirements. J Gerontol Nurs. 2015;41(8): 21-31.

35. Lampit A, Hallock H, Valenzuela M. Computerized cognitive training in cognitively healthy older adults: a systematic review and meta-analysis of effect modifiers. PLoS Med. 2014;11(11):e1001756.

36. Colcombe SJ, Erickson KI, Scalf PE, et al. Aerobic exercise training increases brain volume in aging humans. J Gerontol A Biol Sci Med Sci. 2006;61(11):1166-1170.

37. Simoni D, Rubbieri G, Baccini M, et al. Different motor tasks impact differently on cognitive performance of older persons during dual task tests. Clin Biomech (Bristol, Avon). 2013;28(6):692-696.

38. Valls-Pedret C, Sala-Vila A, Serra-Mir M, et al. Mediterranean diet and age-related cognitive decline: a randomized clinical trial. JAMA Intern Med. 2015;175(7):1094-1103.

39. Singh B, Parsaik AK, Mielke MM, et al. Association of Mediterranean diet with mild cognitive impairment and Alzheimer's disease: a systematic review and meta-analysis. J Alzheimers Dis. 2014;39(2): 271-282.

40. Klimova B, Kuca K. Speech and language impairments in dementia - a mini review. J Appl Biomed. 2016;14(2):97-103.

41. Klimova B, Kuca K. Multi-nutrient dietary intervention approach to the management of Alzheimer's disease - a mini-review. Current Alzheimer Research. Epub 2016 Jun 2.

42. Bugos JA, Perlstein WM, McCrae CS, Brophy TS, Bedenbaugh PH. Individualized piano instruction enhances executive functioning and working memory in older adults. Aging Ment Health. 2007;11(4): 464-471.

43. Tai SY, Wang LC, Yang YH. Effect of music intervention on the cognitive and depression status of senior apartment residents in Taiwan. Neuropsychiatr Dis Treat. 2015;11:1449-1454.

44. Craik FIM, Bialystock E, Freedman M. Delaying the onset of Alzheimer's disease: bilingualism as a form of cognitive reserve. Neurology. 2010;75(19):1726-1729.

45. Anderson-Hanley C, Arciero PJ, Brickman AM, et al. Exergaming and older adult cognition: a cluster randomized clinical trial. Am J Prev Med. 2012;42(2):109-119.

46. Sato D, Seko C, Hashitomi T, Sengoku Y, Nomura T. Differential effects of water-based exercise on the cognitive function in independent elderly adults. Aging Clin Exp Res. 2015;27(2):149-159.

47. Klimova B, Kuca K. Alzheimer's disease: potential preventive, noninvasive, intervention strategies in lowering the risk of cognitive decline - a review study. JAB. 2015;13(4):257-261.

48. Klimova B, Maresova P, Valis M, Hort J, Kuca K. Alzheimer's disease and language impairments: social intervention and medical treatment. Clin Interv Aging. 2015;10:1401-1408.

49. Maresova P, Mohleska H, Kuca K. Social and family load of Alzheimer's disease. Appl Econ. 2015;48(1):1936-1948.

50. Mohelska H, Maresova P, Valis M, Kuca K. Alzheimer's disease and its treatment costs: case study in the Czech Republic. Neuropsychiatr Dis Treat. 2015;11:2349-2354.

51. Melby-Lervag M, Hulme C. There is no convincing evidence that working memory training is effective: a reply to Au et al (2014) and Karbach and Verhaeghen (2014). Psychon Bull Rev. 2016;23(1):324-330.

52. Melby-Lervag $\mathrm{M}$, Hulme $\mathrm{C}$. Is working memory training effective? A meta-analytic review. Dev Psychol. 2013;49(2):270-291.

53. McAvinue LP, Golemme M, Castorina M, et al. An evaluation of a working memory training scheme in older adults. Front Aging Neurosci. 2013;5:20. 
Clinical Interventions in Aging

\section{Publish your work in this journal}

Clinical Interventions in Aging is an international, peer-reviewed journal focusing on evidence-based reports on the value or lack thereof of treatments intended to prevent or delay the onset of maladaptive correlates of aging in human beings. This journal is indexed on PubMed Central, MedLine,

CAS, Scopus and the Elsevier Bibliographic databases. The manuscript management system is completely online and includes a very quick and fair peer-review system, which is all easy to use. Visit http://www.dovepress. $\mathrm{com} /$ testimonials.php to read real quotes from published authors.

Submit your manuscript here: http://www.dovepress.com/clinical-interventions-in-aging-journal 